\title{
SUGGESTIONS OF MOVEMENT: Voice and Sonic Atmospheres in Mauritian Muslim Devotional Practices
}

\author{
PATRICK EISENLOHR \\ University of Göttingen \\ (D) http:/ / orcid.org/0000-0003-4843-4169
}

One afternoon in July 2010, I was sitting in Shareef's living room in a village in central Mauritius. Shareef is a schoolteacher and was also the president (mutawalli) of the local mosque. He is widely known in Mauritius as a reciter of na't, a genre of Urdu devotional poetry that honors the Prophet Muhammad. In collaboration with other Mauritian reciters of na't (na't khwan), he has released nine collections of na't audio-CD recordings, and he has more recently also published na't recordings on YouTube. At the beginning of our conversation I had asked him for an example of what he thought was an appropriate way of reciting na't. As we were talking about events that had happened in our lives since our first encounter some seven years earlier, Shareef switched from Mauritian Creole, the predominant French-lexifier vernacular language of Mauritius in which we conversed, ${ }^{1}$ to Urdu and suddenly started reciting. I had reached his house just before a heavy rain set in, darkening the sky, and now the hissing sounds of car and bus tires rolling on wet asphalt entered through the window from the nearby main road that passed along the edge of the village. In a slow, elegiac air, Shareef recited two lines of na't poetry:

CULTURAL ANTHROPOLOGY, Vol. 33, Issue 1, pp. 32-57, ISSN 0886-7356, online ISSN 1548-1360. (C) American Anthropological Association 2018. Cultural Anthropology journal content published since 2014 is freely available to download, save, reproduce, and transmit for noncommercial, scholarly, and educational purposes. Reproduction and transmission of journal content for the above purposes should credit the author and original source. Use, reproduction, or distribution of journal content for commercial purposes requires additional permissions from the American Anthropological Association; please contact permissions@americananthro.org.DOI: 10.14506/ca33.1.02 
$\bar{A} j$ ashk merī na't sunāye to ajab kyā

Sunkar voh mujhe pās bulāye to ajab kyā
What if my tears would recite na't today? O what wonder this would be What if he [the Prophet] listened, calling me to be close to him? $\mathrm{O}$ what wonder this would be

By way of explanation, Shareef added:

What I want to say is, if one day Huzur [the Prophet] hears my na' $t$ and then he says, ey, you are too far away, come close to me and come and recite this in front of my tomb, how wonderful this would be. But if I go to a mehfil [a devotional gathering], those who are there have a booklet with the text of the na't. And then when they sit there they start reciting like this.

Shareef then launched into a rhythmic air, reciting the same two lines at much greater speed, his vocal expression suggesting an entirely different, more distanced mood.

$\bar{A} j$ ashk merī na't sunāye to ajab kyā

Sunkar voh mujhe pās bulāye to ajab kyā
What if my tears would recite na't today? O what wonder this would be What if he [the Prophet] listened, calling me to be close to him? $\mathrm{O}$ what wonder this would be

Shareef continued: "Beh, you see, it is devoid of any emotion! There is no emotion, there is none of the sentiment I try to transmit. Well, I said to myself, I have to record my recitations. Just to let people know what the original air is that one has to put into the na ' $t$ when reciting it." Shareef stressed how reciting exactly the same lines of poetic text might have very different, indeed opposite effects depending on the mode and style of vocal rendering. For Shareef, the poetic texts recited in a performance of na' $t$ are of course highly important; indeed, they are sometimes even the focus of disputes. However, in our conversation and his reciting of examples Shareef made it clear that the sonic rendering of the poetry was also of crucial significance for a successful recital. Both poetic discourse and its appropriate vocal performance stirred feelings of affection for the Prophet among those listening to the poetry, provoking the ardent wish to be close to him. 
Shareef's comments and vocal demonstration thus raised the issue of the voice and its effects in several ways. He pointed to the intertwining of the discursive and sonic dimensions of the voice, a theme that has lately gained increased attention in anthropology (Kunreuther 2006, 2014; Weidman 2006, 2014; Harkness 2011, 2014; Faudree 2012; Briggs 2014; Jacobsen-Bia 2014; Bakker Kellogg 2015). More broadly, voice has emerged as a pivotal concept in the discipline, bringing together a range of research directions on subjectivity, language, and sound. Critiques of the established logocentric paradigm of the voice as the expression of a unified, authorial self have become increasingly widespread in recent years. For example, inspired by Mikhail Bakhtin's (1981) theorizing of polyphony in discourse and Erving Goffman's (1974) work on fragmentary and shifting participant roles in interaction, linguistic anthropologists have demonstrated the multiplicity of stances that speakers can inhabit in a single utterance (Levinson 1988; Irvine 1996). This line of work on voicing has demonstrated that a subject's voice is the outcome of complex social processes, in which voice refers to "the linguistic construction of social personae" (Keane 1999, 171). Subjects can inhabit and rapidly shift among a plurality of recognizably other, typified voices, positioning themselves vis-à-vis such cited voice-utterances in different ways (Hill 1995; Agha 2005; Keane 2011). Breaking up the equation of voice with a subject's intentionality and authorial agency, this strand of research has drawn attention to the fractured multiplicity that often characterizes the links between voice and subjectivity.

This research tradition has usefully complicated the identification of a single voice with a single subject, which lies at the heart of the common use of the category of voice as a metaphor for a subject's agency and intentionality. It has, however, paid far less attention to the embodied voice's sonic materiality. More recently, a number of anthropologists have sought to overcome the "oppositions between a masculinized, signifying, authorial voice, and a feminized, sonic, material vocality" (Weidman 2015, 240) pervading North Atlantic scholarship about the voice. These anthropological interventions reject the notion of a logocentric authorial voice. They also position themselves against a one-sided valorization of the voice as "the materiality of the body speaking its mother tongue" (Barthes 2012, 506), or alternatively, as an autonomous object, an "object voice" (Dolar 2006, 11) that from a psychoanalytical perspective exceeds subjectivity and signification. Anthropological approaches to what Nicholas Harkness $(2014,12)$ has called the "phonosonic nexus" have drawn analytic connections between the historically grounded analysis of social values with which those performing vocal 
sound align themselves and the sonic materialities of the voice, showing how the latter function as integral parts of emerging subjectivities and social formations (Weidman 2006; Harkness 2014; Kunreuther 2014).

While I am inspired by this recent anthropological turn toward the sonic dimensions of the voice, in this article I would like to shift my focus away from the issue of subjectivity to the body as the site where vocal sound originates, reverberates, and rebounds. More specifically, I would like to point to the centrality of the phenomenological felt-body (Leib) in contradistinction to the physical body (Körper) for the analysis of voice. The distinction between Leib and Körper was first made by Helmuth Plessner (1982) and adopted by Edmund Husserl (1973, 57) and Maurice Merleau-Ponty (2002, 329-30). ${ }^{2}$ I specifically draw on Hermann Schmitz's (1965) more recent explication of the notion of Leib as reaching beyond the boundaries of the physical body. The purchase of the notion of the felt-body in this context is that the felt-body transcends the limits of the material body as it is commonly conceived and thereby helps to do justice to sound as a material phenomenon that ignores the boundaries of bodies. The feltbody is the space of what is felt to pertain to the body beyond what are normally regarded as its limits, thus complicating distinctions between inside and outside. For this reason, the notion of the felt-body proves useful for grasping the intermingling of sonic phenomena with human bodies. Drawing on newer approaches in phenomenology, I suggest that an analytic of atmospheres can provide useful leads for a better understanding of vocal sound as a force that is socially meaningful but at the same time often appears ineffable in the way it generates its effects. Arguing against the increasingly widespread identification of the sonic with affect among scholars in the field of sound studies, I suggest atmospheres as a conceptual tool that offers a way out of persistent dualisms between mind and body, as well as signification and affect, which continue to haunt much writing about the voice and sound more broadly.

\section{DEVOTIONAL PERFORMANCES}

In this article I am concerned with the recitation of na't, devotional poetry in honor of the Prophet Muhammad. The recitation of these hymns and poems, usually in Urdu, is very popular in South Asia and the South Asian diasporas. In my research, I have focused on the performance of this poetic genre among Muslims in Mauritius, where approximately 70 percent of the population is of Indian origin. This devotional practice is particularly widespread among the followers of the Ahl-e Sunnat wa Jama'at, an Islamic reform movement with origins 
in late nineteenth-century colonial India that fuses 'ulema-based Islam, which is based on communities of Islamic scholars, with the Sufi tradition (Sanyal 1996). For many followers of this South Asian Islamic tradition, the extolling and praising of the Prophet that is at the center of the recitals aims to bring about his spiritual presence. Gaining access to God via a spiritual intermediary, such as a saint or the Prophet, is in turn one of the hallmarks of Sufi traditions of Islam. For this reason, the practice of collectively reciting na't to personally apprehend the Prophet has also invited criticism by followers of other, more purist Islamic currents who consider the emphasis on spiritual mediation and the exuberant praise of the Prophet a denial of the unicity of God. Many of these critics hail from the Deobandi and Salafi traditions, both of which are also present in Mauritius, the former especially through the Deoband-affiliated missionary movement Tablighi Jama'at. In recent decades, these two traditions have made steady inroads into the constituency of the Ahl-e Sunnat wa Jama'at, as has happened in India and Pakistan.

Islamic traditions have long regarded vocal recital as a privileged avenue to divine presence. A powerful Qur'anic paradigm according to which the reciting voice is the site where God manifests himself in this world has had a profound impact on Islamic ritual practices and scholarly learning (Nelson 2001; Gade 2006; Jouili and Moors 2014). This religious paradigm presents an interesting variation on the theme of the voice as an other - here, the presence of God - that has come to play a key role in anthropological and psychoanalytical engagements with the voice. While different from the recitation of scripture, Mauritian Muslims' recitation of na' $t$ is also informed by this particular sensibility to vocal sound as divine manifestation.

In its textual and discursive dimensions, na't not only features exuberant praise of the Prophet and expressions of utmost devotional and attachment to him. Many na't also center on the theme of Medina, considered to be the Prophet's favorite city. The sights and landmarks of the city are lauded in the most enthusiastic and affectionate ways, and the devotees' ardent wish to travel to Medina underlines the poetic role of Medina as a stand-in for the presence of the Prophet. Accordingly, the devotional poems revolving around a longing for Medina are widely taken to be expressions of the desire to personally encounter the Prophet. Moreover, in a process of voicing, the lead reciters seek to appropriate the voice of prominent author-saints who are assumed to have been the composers of many well-known na't, merging these poetic words of such saints with their own responsibility and agency as an expression of their personal de- 
votion to the Prophet. The performance of the poetry is thus markedly polyphonic in a Bakhtinian sense, as the reciters combine their personal agency with those of divinely inspired saint-poets. In Goffmanian terms, this results in an overlap of the participant roles of composer, sponsor, and relayer (Goffman 1974; Levinson 1988), giving the voice of the na't khwan a complex, multifaceted character resulting from social processes of discourse circulation and appropriation.

As important as these discursive dimensions are for a successful performance of na't, for Shareef and others among my Mauritian Muslim interlocutors, its sonic dimensions were also crucial. In fact, many of the conversations about na ' $t$ performances that I had in Mauritius centered on the qualities of the voice a good na't khwan should have. Several of my respondents described how a na't khwan's voice would deeply touch them, stirring love for the Prophet in them while moving them profoundly in ways they often struggled to describe.

\section{ATMOSPHERES}

The contagious quality of the feelings that a good na't recital spreads was a recurrent topic in my conversations with my Mauritian interlocutors. Farhad, a young na't khwan and Urdu teacher said:

When an ordinary person reads na't, the others who are listening will just sit there. They will appreciate the recital, but they will stay silent. However, we who are used to reciting na't, when a na't khwan recites we are not able to remain silent any more, we have to join in. We call that jawab [Urdu for answer]. Once we join in, he [the na't khwan] is happy; when he is happy that means he gains respect and his message comes across, and he recites even better, he gives everything.

According to Farhad, the voice of a skilled na' $t$ khwan compels listeners to respond, joining into shared exclamation. In another conversation he pointed out that when provoking such a response, the voice would literally "grip" the audience with force. One of his friends, Mohamed, a former school principal, even spoke of audiences seized by the force of a na't khwan as "vibrating" in unison. As several of my interlocutors stressed, to be able to do so, a na 't khwan's voice would have to be "touching" those exposed to it. How can one account for the sensations of touch and vibrating movement that my respondents described? Clearly, an analysis of the discursive dimensions of the poetry alone is not sufficient to grasp the sensations and tangible effects of the voice that Farhad and others describe. The widespread use of voice as a category indicating subject positions, interactional 
stances, and participant roles in the traditions of Mikhail Bakhtin and Erving Goffman will not get us much closer to the bodily felt effects of vocal sound that appear to be so central to the performance of na't as a devotional practice. For this, we need an approach that takes sound seriously, doing justice to the kinds of knowledge and effects mediated by it.

My interlocutors often found it difficult to make clear what exactly the voice of a na't khwan did to them, considering its effects both ineffable and profound. Such vagueness in the face of an undeniable presence lies behind the power of na 't khwans' voices to provoke spontaneous responses among their audiences, and to carry them along in ways that go beyond the metaphorical. Nevertheless, several of my interlocutors did come forward with descriptions of their culturally embedded perceptions of sound, thereby pointing to the crucial role of auditory cultures, learned techniques of attending to sonic events that are part of larger sociocultural complexes, such as a particular religious tradition (Feld 1996; Schmidt 2000; Bull and Back 2003; Sterne 2003; Erlmann 2004, Feld et al. 2004, Kane 2015, 15). A skillful vocal performance would make Mohamed feel "transported elsewhere, to a better place.” In many na't, Medina, as the Prophet's favorite city, is exuberantly extolled as such a desirable destination, with the devotee longing to travel there, hoping to encounter the presence of the Prophet himself. That is, the voice of a na't khwan would move listeners to this pious destination, close to the Prophet.

Na't khwans' voices were described as producing sonic events that effected profound transformations in listeners. A common thread in the responses my interlocutors provided when trying to describe their experiences of being touched by a good na't khwan's voice were sensations of movement exerted on them, making such phrases as "making one vibrate" or "moving one to a different place" common. One image that Shareef used to describe such an experience of felt movement was "getting on a bus," traveling toward a desired destination through sonic affection. The sonic dynamics of a voice would then result in changes in the body's felt location in space. I suggest that the analytic of sonic atmospheres that I describe in this essay can offer a promising approach to understand how such movements can be more than poetic metaphors, having a very literal base as well.

The bodily encounter with voice was the dimension of na' $t$ performances that my Mauritian Muslim interlocutors found most powerful, though they struggled to describe what exactly these encounters consisted of. Through my conversations with them, and during my attendance of mahfil-e mawlud (devotional gatherings where na't is recited), it became clear that these felt encounters re- 
volved around moments of sonic intensification, that is, around marked instances of vocally enacted movement that affected listeners in a somatic register.

Where does this peculiar power of voices come from? How can we account for its capacity to move people in ways that go beyond the metaphoric? I suggest that such effects can best be understood as the workings of sonic atmospheres. Here I draw on recent work in music studies that treats sonic phenomena as atmospheres (Abels 2013, 2017). For such neo-phenomenologists as Gernot Böhme and Hermann Schmitz, atmospheres-including those containing sonic dimensions - are "ecstasies of the thing" (Böhme 1993, 110), exuding from people, objects, or their combinations. Atmospheres are quasi-objective entities that spread in a given space, touching and enveloping the bodies of those perceiving them in a way that exceed single, definite sensory impressions. Far from being a matter of subjectivist interiority, feelings are atmospheres poured into a space where they encounter and impact humans, similar to the sensations of being in darkness or warmth (Schmitz, Müllan, and Slaby 2011, 255). Sound and sonic events in turn provide concrete, empirically observable instantiations of Böhme's notion of atmospheres as "ecstasies of the thing." They exist in time, can be measured, and propagate through space. For Schmitz (2014, 30; author's translation), sound and sonic events rank among the foremost instances of atmospheres as "the occupying of a nondimensional space or area within the range of experienced presence." Sound waves come into existence when objects or human bodies disturb a medium such as air, enveloping and often transductively entering the bodies of those perceiving them, thereby weakening their boundaries. Sound waves propagating through the medium of air as differences in air pressure cannot only be perceived by the hearing apparatus but can also potentially reverberate in and be sensed by the entire body, by its flesh. This is an experience familiar to anyone who has felt the bass resonate in one's own body in a dance club (Henriques 2003). Unlike the notion of soundscape, which in its analogy to landscape suggests a three-dimensional auditory space that a listener is confronted with, an analytic of atmospheres attends to the intermingling of sound and the felt-body. ${ }^{3}$ In this somatic dimension, sound is one of our principal modes of experiential commingling with the world (Ingold 2007, 11). According to Böhme (2000, 18), the concrete role that sonic phenomena play in such commingling is that they affect the felt-body's sense of spatiality:

Listeners will sense tones, voices, sounds as modifications of their own space of being. Human beings who listen in this way are dangerously open, they 
release themselves into the world and can therefore be struck by acoustic events. . . . Listening is a being-beside-yourself (außer-sich-sein); it can for this reason be the joyful experience of discovering oneself to be alive.

Connecting these insights to a larger theory of sonic atmospheres, Böhme (2000, 16) writes about the often remarked-upon emotional force and ineffability of musical effects:

The discovery that music is the fundamental atmospheric art has solved an old, always annoying and yet inescapable problem of musical theory, i.e. the question: of what does music's so-called emotional effect actually consist? . . . The aesthetics of atmospheres gives a simple answer to the question: music as such is a modification of space as it is experienced by the body. Music forms and informs the listener's sense of self (das Sichbefinden) in a space; it reaches directly into his or her corporeal economy.

Concerning the particular nondiscursive power of voices on those exposed to them, Böhme (2009, 30-31; author's translation) points to the ways in which vocal sound manipulates the felt-body's sense of being in space:

We listen to a voice in space. We are affectively struck by the voice because we are modified in our own presence in space through the voices we hear. To be present in a space means to reach out into this space through the sensing of the felt-body [durch das leibliche Spüren]. This occurs through feeling oneself contracted or expanded, pushed down or lifted up and much more. . . The extraordinary effect of voices on our present emotional state is due to them immediately modifying our presence in space as sensed by the felt-body. They can make one contracted or expanded, they can be elevating and redeeming, or dampening and frightening. As tones are called high and low, having a broad base (Greek: barus), or pointed and sharp (Greek: oxus), so do our sensations follow the suggestive impressions [Anmutungen] of such tones by inviting or forcing us to be present in space in this or that way with the sensing of our felt-body.

In this quote, Böhme points to how vocal sound manipulates the felt-body's sense of locating itself in space in concrete ways. For him, this occurs through subtle sensations of spatial movement enacted on the felt-body through the force of sound. Böhme's arguments about vocal sound as modifiying the felt-body's sense of being in space align with Schmitz's $(2014,85)$ notion of atmospheres as con- 
taining suggestions of movement (Bewegungssuggestionen). In the case of sonic phenomena, several acoustic parameters such as loudness, pitch, and timbre are involved in the patterning of what Böhme calls "modifications" of the space felt by the body. In other words, the dynamics of sound, including vocal sound, enact such suggestions of movement. Sound's seizing of the phenomenological felt-body is driven by suggestions of movement that reach into corporeal economies, altering the space sensed by the felt-body. The propositions of this phenomenological theory of sonic atmospheres in turn bear striking resemblance to my Mauritian Muslim interlocutors' descriptions of sonic perception in their devotional practices, descriptions that revolved around sensations of touch and spatial movement. ${ }^{4}$

This analytical route requires closer attention to the particularities of sonic phenomena than has so far been common in anthropological writings on voice. For instance, recordings of performances by well-known Mauritian na ' $t$ khwan are characterized by variations in vocal dynamics including loudness (perceived volume), pitch (fundamental frequency), and timbre. Also, professional recordings of na' $t$ recitals in Mauritius and South Asia nowadays typically feature a marked reverb, which leads to a distinct effect that my interlocutors referred to as "echo." As a result, all acoustic events are multiplied and thereby intensified. A key characteristic of vocal dynamics in the recitation of this genre is recurring moments of sudden intensification, frequently after a short pause in the recitation, that coincide with a marked increase in volume and pitch. At the same time, at the level of timbre, a greater concentration of acoustic energy (the pressure level of sound waves) occurs in frequency bins far above the fundamental frequency: specifically, in the three- to five-thousand-hertz range described by Johan Sundberg (1974) as the "singer's formant." That is, such moments of vocal intensification do not just consist in an abrupt increase in perceived volume and pitch, but also changes in timbre. The latter refers to the shape of and energy within the formant or overtone structure above the fundamental frequency that makes up complex sounds such as a voice. Timbre enables us to identify the sources of complex sounds, and to distinguish between the sounds of an engine, a violin, a voice, or between different individual voices. As mentioned already, na 't recordings feature a reverb throughout, leading to the multiplication of acoustic events.

In such moments of intensification, the voice enacts suggestions of movement in several ways. The combined increase in loudness, pitch, and the shift of acoustic energy to higher-frequency bands within the spectral envelope of vocal sounds carry out a movement of enrapture that my Mauritian Muslim respondents 
described as being beside oneself, as being moved up and away to another place. As the discursive dimensions of the recital often qualify such sonically enacted movement as being directed to Medina, my respondents also spoke of the sensation of being carried away toward Medina and the desired encounter with the Prophet. As Mohamed put it when describing how the voice of Owais Qadri, a renowned Pakistani na't khwan, affected him: "People like him, when they recite they make you vibrate. Why? Because the way they are reciting, you will not feel you are here; you will feel you are in Medina. They have taken you to Medina."

To do justice to sound and prevent its immediate reduction to language in analysis, some formal engagement with sound's characteristics is necessary. This is particularly relevant for the study of sound in Islamic contexts, where previous ethnographic work has mainly attended to verbal descriptions of sound, its perception, and its effects (Hirschkind 2006; Kapchan 2008, 2009). Discursive renderings of sound and its perception, like those offered by my interlocutors in Mauritius and those found in other ethnographic studies, remain central to anthropological approaches to the sonic dimensions of Islam. Nevertheless, the analysis also has to go beyond the discursive if one wants to do justice to sound as a separate modality of creating knowledge and meanings not reducible to language. Such an approach also necessitates paying close attention to sound's formal features and characteristics, as well as their dynamics as sonic events unfold. The diagrams of spectrographic and waveform analysis below are not intended to tell a superior scientific truth but to complement what my interlocutors said about Islamic sounds, serving as a recognition that sound requires modalities of access beyond language.

The spectrograms measure movements in timbre and fundamental frequency across a short stretch of time. The $\mathrm{X}$-axis measures time, while the $\mathrm{Y}$-axis measures the frequency of sound waves in hertz. The acoustic energy of complex sounds such as a voice is not evenly distributed along a spectrum of frequencies, but coalesces around particular frequency bands that look like layers on the spectrogram. These build the structure of overtones above the fundamental frequency that creates the sound's timbre. Very important for timbre, some formants or overtones (the layers along particular frequency bands) contain more acoustic energy than others, which the spectrogram makes visible by a color continuum ranging from green (low) to yellow (medium) to orange (high). The waveform diagrams likewise measure sonic dynamics over time; the sound waves are centered on a zero axis, representing the given atmospheric air pressure, while the waves stretch between hypothetical 1 and -1 values that represent the waves' 
pressure. The greater the amplitude of a wave, the greater its pressure differential and, with some qualifications, the greater its volume. A graph additionally tracks the fundamental frequency of the sounds below the waveform. ${ }^{6}$

Examining the sonic dynamics of na't recitation, consider the following example from a recording produced and circulated in Mauritius. In this na't, the reciter, assuming the "I" of the devotional discourse, compares the perfect figure of the Prophet to his own abject existence as an ordinary sinning person, thereby further exalting the Prophet while imploring him for intercession on the reciter's behalf. The familiar Medina motif also features prominently in this panegyric poem. The reciter lauds the supernatural splendor of the Prophet's favorite city, begging to be able to go there. In directly addressing the Prophet, the na't khwan appropriates the voice of the saint-poet who presumably composed the poetry, entering into a personal conversation with the Prophet.

Voh madīna nagīna hai jo 'arsh kā

Voh madīna bahram jo banā farsh kā
That city of Madina that is the gem of the heavenly throne

That city of Madina is also the dream of the world below

As significant as these discursive dimensions of the poetry are for the performance, the sonic dimensions of the na 't khwan's voice play a decisive role. This is because the na't khwan's voice also enacts a movement of enrapture through the medium of sound. Over these two lines, the voice carries out a movement of being carried away that coincides with the discursively expressed wish to travel to Medina to personally encounter the Prophet.

Audio 1. Excerpt from Disc 1, Track 5 of Shareef Chady's undated recording Naaté-Rasool $(S A W)$, produced by Étoile Brilliant Sound.

In this excerpt, the spectrogram shows an abrupt increase of acoustic energy in the three- to five-thousand-hertz range at the onset of the phrase, marked by red-orange coloring. As is evident from both the spectrogram and the graph tracking fundamental frequency, the pitch peaks on the syllable -gi of nagina, which is especially drawn out, with the spectrogram and the pitch tracker illus- 


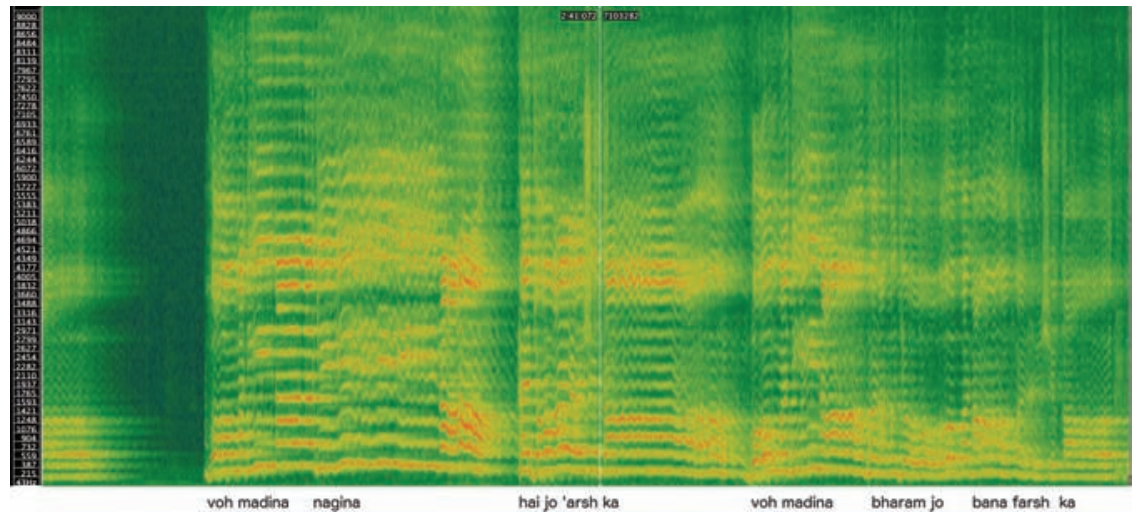

Figure 1. Spectrogram of the sung words voh madina nagina hai. Image created by Patrick Eisenlohr.

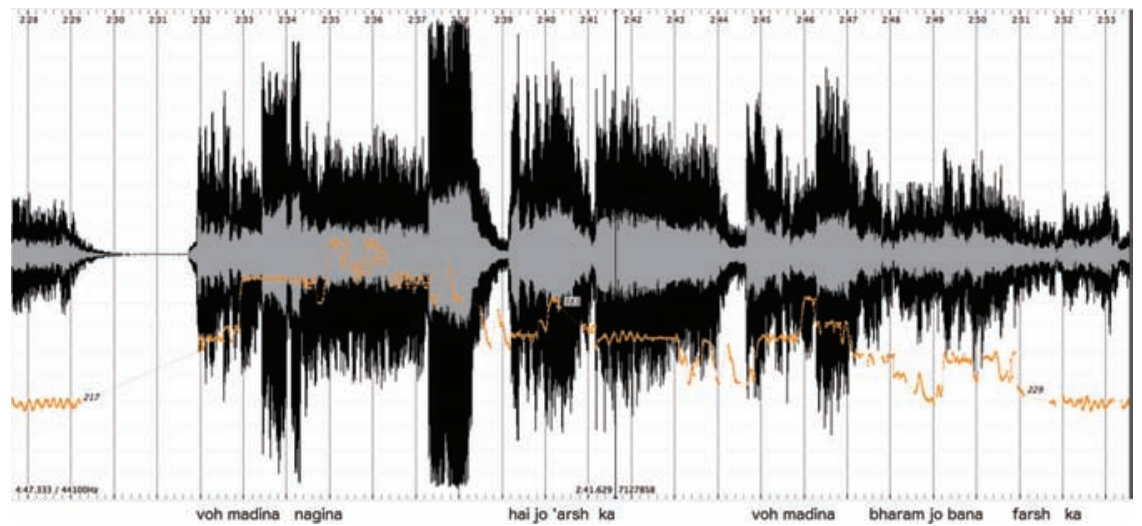

Figure 2. Waveform and fundamental frequency of the sung words voh madina nagina hai. Image created by Patrick Eisenlohr.

trating the very strong modulation of the na't khwan's voice. As the comparison of the spectrogram with the waveform makes clear, the appearance of the "singer's formant" (Sundberg 1974) in the timbre visible in the spectrogram also coincides with an abrupt increase in loudness evident in the waveform that finally peaks on the syllable -na of nagina. The marked reverb applied throughout is especially evident in the echoing decay of the previous phrase into the short pause of about 2.2 seconds before the phrase's sudden onset and attack, visible on the left of the spectrogram. In the second line, voh madina bahram jo bana farsh kā, the concentration of acoustic energy in the three- to five-thousand-hertz range disappears after the second rendering of madina, which also coincides with a decrease in 
loudness and pitch. Spectrogram, waveform, and pitch tracking very clearly illustrate the sonic dynamics of the two parts of the phrase as a movement of intensification or contraction and a following countermovement of extension or relaxation.

Both the spectrogram and the waveform with pitch tracker are diagrams of the sonic movements performed. However, it is important to realize that these enacted movements go beyond the metaphoric. This is because the sonic dynamics I have detailed above are not just representations of movements, but actually enact suggestions of movement on the felt-bodies of listeners, encountering and affecting them through the medium of sound. The phrase above begins with a movement of rapture and upward expansion, suggesting an overcoming of the boundaries of the self and a spatial removal to another place. The discursive dimensions of the poetry, with its elaboration of the Medina motif, in turn specify such transcending of the self, its sonic reaching out, and its transportation to another place as Islamic in a certain way. In a devotional idiom, it is cast as the travel to the wonderful city of Medina to encounter the Prophet. The second part of the phrase finally features a relaxation of the first part's expansive sonic movement, returning to its starting point, thereby enabling its repetition.

Intense, sonically enacted suggestions of movement are also evident in the following excerpt from a different recording. The text of the na' $t$ reads:

Kul jahān malik aur jo kī roṭ̂̄ He owns the entire world and he is ghizā content with a plain flatbread as food

As the discursive dimensions of the performance exalt the exemplary character and modesty of the Prophet, the dramatic sonic movement that the na 't khwan's voice carries out is palpable. Here, we can see a rise in fundamental frequency (pitch) and loudness, with a buildup of acoustic energy in the three- to fivethousand-hertz range.

Audio 2. Excerpt from Disc 2, Track 10 of the undated recording Ashiqué Rassool Shah Ahmad Razaa Ka Kalam, by Dar-ul-uloom Imam Ahmad Raza.

The dynamics of the reverb effect also prove highly salient in this excerpt. Not just at the end of the phrase, but especially in the approximately nine- 


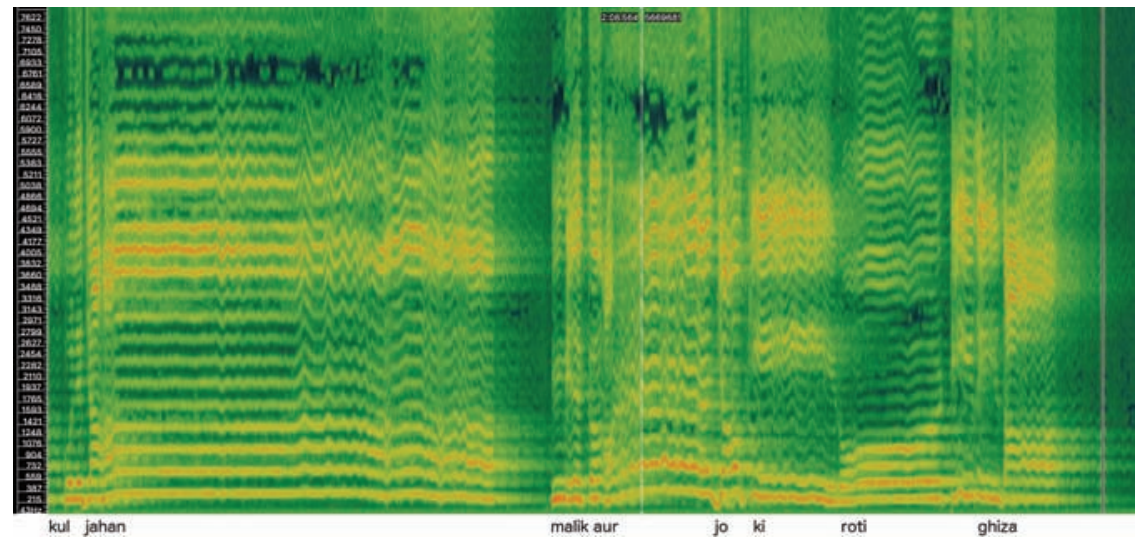

Figure 3. Spectrogram of the sung words kul jahān malik aur jo kī roṭi ghizā. Image created by Patrick Eisenlohr.

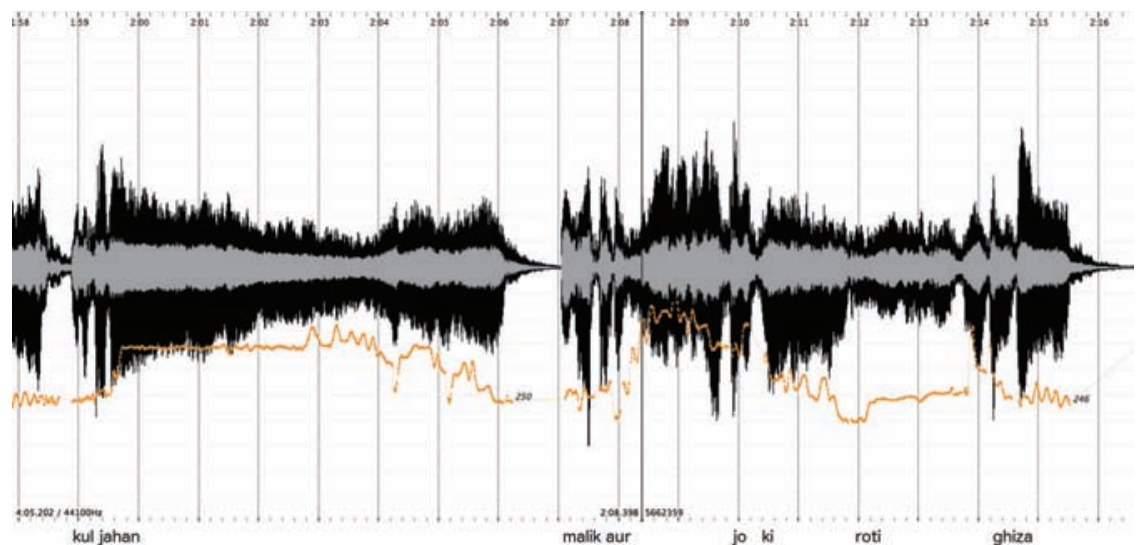

Figure 4. Waveform and fundamental frequency of the sung words kul jahān malik aur jo kī roțī ghizā. Image created by Patrick Eisenlohr.

hundred-millisecond pause after the drawn-out jahan in the middle of the phrase, the reverb is very much in evidence, the spectrogram showing a reverb time of about two hundred milliseconds. The latter time is clearly located above the threshold of sixty milliseconds at which most humans perceive sounds set off from each other by such an interval as separate phenomena (Benade 1990, 210). As a result, a powerful echo effect gives the impression of multiplying the articulations of the na't khwan's voice.

Yet the most striking feature of this excerpt is the drawing out of the second syllable - the -hān of jahān for about 3.5 seconds. The na't khwan then breaks with the tone held for this period in a modulating movement for another two 
seconds before pausing. The spectrogram also reveals an extreme vibrato on all harmonies of the spectrum. After the brief pause, the na 't khwan's voice resumes with a movement culminating with a peak on the words aur jo kī, displaying a coincidence of a rise in pitch and loudness with another concentration of acoustic energy in the formants of the three- to five-thousand-hertz range. This coinciding of several acoustic parameters of intensification creates a sonic movement of being carried away in rapture, a movement that also overcomes the boundaries of the self.

To sum up, in these examples the reciting voice enacts suggestions of movement through the medium of sound. These movements are not merely metaphoric; rather, the sonic dynamics that carry them out act on the felt-bodies of those exposed to them in analogous fashion. The sonically enacted movements thereby act as atmospheres in Böhme's and Schmitz's sense, enveloping and suffusing listeners' felt-bodies while modifying their spatial economies through suggestions of movement. At the same time, the poetic discourse recited qualifies such suggestions of movement as Islamic in a particular way, as an overcoming of the boundaries of the self that is resonant with Sufi traditions and that involves travel to a desired destination, Medina, in order to personally encounter the Prophet. The na't khwan's voice unites these two dimensions of na't recital as a devotional practice, generating sonic atmospheres that enact movements of rapture and uttering poetry that praises and expresses deep devotion and longing for the Prophet Muhammad.

In the examples I have discussed, the sonic dimensions of voice and the discursive aspects of the recital work hand in hand, mutually reinforcing each other. Nevertheless, the sonic modalities in principle remain independent from discursive meaning. This is because sound constitutes a phenomenon in its own right, with its own modalities of knowledge and meaning-making. In my examples, the meanings generated by sonic movement and the discursive aspects of recitation align, but there remains a difference in kind. This differentiation is related to what Schmitz (2005, 104; author's translation) has called the "holistic internally diffuse meaningfulness" of atmospheres, including sonic atmospheres. With this he meant that atmospheres generate an excess and multiplicity of meaning that is hard to specify clearly and that is impossible to describe in an exhaustive way. Its characteristics blend into each other to such an extent that they are difficult to distinguish in description. While multiplicity of meaning certainly also pertains to discourse, especially poetic discourse, the latter qualifies the meaning generated in sonic movement as Islamic, and even sectarian, in a much more 
specific way. In other words, there is no definite link between particular sonic movements and a particular, discursively elaborated Islamic theme. Rather, in $n a^{\prime} t$ as a form of devotional recitation, discourse specifies and fine-tunes the diffuse meaningfulness of sonic movements, suggesting spatial displacement and a longing to be elsewhere as an Islamic form of spiritual travel toward a personal encounter with the Prophet. Likewise, when my Mauritian Muslim interlocutors listen to na't, they do so with knowledge of this Islamic way of interpreting sonic movements. In other words, their learned auditory techniques also contribute to the alignment of sonic movement and spiritual travel.

\section{AGAINST AFFECT: Sonic Suggestions of Movement and Signification}

My discussion of sonically enacted suggestions of movement as a deeply meaningful dimension of Mauritian Muslim devotional practice runs counter to the work of several scholars in the field of sound studies who identify the sonic with affect. Inspired by the ontology of Gilles Deleuze as interpreted by Brian Massumi (2002), several theorists of sound have come to treat the sonic as an exemplification of the material intensities and flows to which they refer as affect, which operate prior to consciousness, signification, and representation. As Eric Shouse (2005) has put it:

An affect is a nonconscious experience of intensity; it is a moment of unformed and unstructured potential. . . . The importance of affect rests upon the fact that in many cases the message consciously received may be of less import to the receiver of that message than his or her nonconscious affective resonance with the source of the message. Music provides perhaps the clearest example of how the intensity of the impingement of sensations on the body can "mean" more to people than meaning itself.

The fact that the sonic comprises vibrational and wave phenomena that often operate outside or beyond the threshold of human perception has led some sonically inclined theorists of affect to take the sonic as a privileged avenue to think about the Deleuzian opposition of the virtual and the actual (Evens 2002, 183; Massumi 2002, 30-31, 62; Goodman 2010). While the actual consists of empirical, seemingly given phenomena, the virtual are the sheer forces of multiplicity and constant differentiation that generate them. Accordingly, actual sonic events stand in deep relations of continuity with the vast spheres of virtual vibrational and wave phenomena from which the former emerge. Will Schrimshaw (2013, 
43) has drawn on the notion of noncochlear sound to designate this realm of implicated acoustic signals from which actual sound emerges, a world of "inaudible yet affective signals, signals that are taken as structurally equivalent to autonomous and infraesthetic affects."

One of the main problems with this alignment of the sonic with affect is that it has led to a categorical distinction between the sonic and signification. For example, taking the sonic as "an asignifying material flux," Christoph Cox (2011, 157) draws an ontology in which the sonic is prior to and excessive of interpretation and representation. Cox hereby extends the "autonomy of affect" (Massumi 2002, 35) to the sonic. Here, the distinction between the realm of the sonic and the realm of signification coincides with a reinstated boundary between the material as the sphere of energetic forces affecting bodies and the mind as the producer of meaning. According to Massumi, the former is necessarily prior to the latter because the mental creation of consciousness and signification always comes a split-second too late. This "half-second delay" (Massumi 2002, 195) is responsible for affect's power: affect, including the sonic in the understanding of the theorists cited above, has always already done its work of traveling through and affecting bodies before subjects even become aware of it and apply signification to its effects. Affect theory's inverted body-mind dualism (see Leys 2011) is the justification for its dismissal of meaning, and has prompted several scholars in sound studies to declare the sonic, aligned with affective forces more generally, as prior to and free from signification.

Yet seen from the vantage point of a phenomenology of atmospheres, sonic dynamics contain suggestions of movement that act on the felt-bodies of those perceiving them. These movements are not linguistic signs, but they are nevertheless highly meaningful. In Peircean terms they contain a combination of iconic and indexical relationships (see Parmentier 1994). Indeed, in the excerpts analyzed earlier, the sonic movements provide diagrams of spiritual travel. According to Charles Sanders Peirce $(1932,157)$, diagrams are icons "which represent the relations ... of the parts of one thing by analogous relations in their own parts." Thus diagrams, such as a map, are iconic signs that depend on the structural resemblance of relations across qualitatively different domains. In this case, the relations between sounds that constitute sonic movements resemble the spatial movements of a devotee pursuing spiritual travel to a desired destination. Most important, these sign relationships are embedded in their material (and more specifically sonic) forms, and are not mental representations applied to materiality after the latter's unfolding. ${ }^{7}$ Therein lies the link between the sonic movements 
I have investigated with the help of spectrographic and waveform analysis and the way my Mauritian Muslim interlocutors described the ways in which they felt moved by the vocal sounds of na' $t$ recitation: it is the iconic relationship between sounds' measurable dynamics and my interlocutors' reported sensations as they were affected by vocal sounds when exercising the auditory techniques that form part of their devotional practices. Taking vocal sound as atmospheric phenomena that mingle with felt-bodies can, in turn, help us understand how such an analogy between sonic movements and my interlocutors' reported sensations comes about.

A reduced, intellectualist understanding of meaning in which materiality and signification inhabit separate realms informs the characterization of the sonic as asignifying. It casts all sonic meaning as Saussurean signs, which impose arbitrary mental forms on an essentially meaning-free material flux. More promising than such a binary opposition between signification and materiality is an approach that not only takes the material as part of signification but also recognizes the possibility of different modalities of meaning in a sonic practice such as na't recitation. These modalities range from the more diffuse meaningfulness of suggestions of movement to more strongly qualified discursive meanings pointing to a particular Islamic tradition. To sum up, then, in contrast to sonically minded versions of affect theory, an analytic of atmospheres overcomes the dualism of materiality and signification. It does justice to the somatic dimensions of sound while enabling us to treat sonic dynamics as deeply meaningful in their nondiscursive musical modes and forms of knowledge.

Affect theory's insistence on the involuntary and often un- or preconscious effects of sonic and vibrational phenomena is also problematic because it sidelines the importance of auditory cultures, the learned techniques of listening embedded in cultural frames to which my interlocutors' descriptions of the power of vocal sound pointed. Defenders of affect theory who subscribe to Massumi's stance on the autonomy of affect might argue that hearing cultures are about interpretation after a "half-second delay," when sonic affect has already done its work regardless of any form of cultural mediation, which always arrives too late. However, the notion of auditory culture is necessary to account for the diversity of auditions that any particular sonic practice is subject to and embedded in. Empirically existing sonic practices cannot be understood separate from the plurality of traditions of listening. Sonic events do not have the same effects on all human actors exposed to them. This is also the case for reciting and listening to na't poetry among Mauritian Muslims, all the more so as the practice has always been em- 
broiled in sectarian differences. A Mauritian Muslim following Salafi traditions might appreciate the beauty of a na't khwan's voice. Nevertheless, he or she is unlikely to be moved by it in the same way as adherents of the Ahl-e Sunnat wa Jama'at are. For the latter, deep devotion and personal affection for the figure of the Prophet is not only central to their tradition. They also seek to bring about the spiritual presence of the Prophet through devotional practices such as mehfile mawlud. The latter would be anathema for a committed Salafi but also to followers of the Tablighi Jama'at, who would take them to be shirk, or associating others with God, thereby compromising the unicity of God in unforgivable ways. Thus, not all Mauritian Muslims are fond of the na't genre and receptive to its call to be closer to the Prophet.

An analytic of atmospheres recognizes sonic phenomena as energetic flows that affect felt-bodies while allowing for the mediation of the sonic through auditory cultures, semiotic ideologies, and other historically and social embedded traditions. As Schmitz (2014, 86-87) has pointed out, atmospheres that are merely observed need to be distinguished from atmospheres as feelings that seize someone in a more thoroughgoing somatic mode. Anthropologists have long argued that bodies are socially shaped and sensitized. This idea also extends to their perception of sound (Downey 2002; Erlmann 2004; Feld et al. 2004; Hirschkind 2006). Bodies need to be attuned to the effects of a devotional practice such as the recitation of na't. Their sociocultural qualification mediates the effects of sonic atmospheres, including the suggestions of movement enacted by them.

\section{CONCLUSION}

In this essay I have made a case for an analytic of atmospheres as a way to understand the seemingly ineffable, yet powerful effects of vocal sound on listeners in an Islamic setting. Such sonic practice produces tangible atmospheres that fill spaces between their sources and felt-bodies, enveloping and suffusing them. Detailed attention to the particularities of sonic phenomena enabled us to see that sonic atmospheres enact suggestions of movement. Sonic atmospheres manipulate felt-bodies' sense of being in space. This phenomenon accounted for the religious sounds' profound somatic effects, often spoken about as sensations of being touched or moved. Arguing against the identification of the sonic with affect in the work of several scholars in the field of sound studies, I have also sought to show that the suggestions of movement enacted in the recitation of na' $t$ poetry are highly meaningful. Far from being a matter of mental representations imposed 
on an essentially asignifying sonic materiality, vocal sound's meaningfulness is internal to the processual nature of its material forms.

The recitation of na't as a devotional practice in Mauritius further qualifies the meaningfulness of sonically generated suggestions of movement as Islamic in a specific sense through poetic and discursive mediation. In this way, recitation brings sonically enacted sensations of a movement elsewhere in alignment with spiritual travel to Medina to personally encounter the Prophet. In Mauritian na 't recitation the sonic and discursive dimensions of the voice therefore operate in tightly interrelated ways.

In my analysis, I have sought to bring together the neo-phenomenological analytic of sonic atmospheres with recent anthropological approaches to the voice that seek to overcome the unproductive dualism of discursive signification and unfathomable sonic materiality that has characterized much writing on the voice in North Atlantic scholarly traditions. Unlike theories of sonic affect, an analytic of atmospheres does justice to somatic effects of vocal sound that often evade discursive rendering. It also treats both sonic and discursive dimensions of voice as fully embedded in particular historical and sociocultural worlds.

\begin{abstract}
In this essay I make a case for the analytic of atmospheres as a way to understand the seemingly ineffable, yet powerful effects of vocal sound on listeners in an Islamic setting. Focusing on the recitation of devotional poetry in honor of the Prophet Muhammad among Mauritian Muslims, I seek to bring together neo-phenomenological approaches to sonic atmospheres with recent anthropological research on the voice that seeks to overcome the opposition of discursive signification and sonic materiality. Detailed examination of sonic events shows that sonic atmospheres enact suggestions of movement that go beyond the metaphorical. Arguing against theories of sonic affect that take the sonic to be an asignifying material flux, I seek to demonstrate that vocal sound's meaningfulness is internal to the processual nature of its material forms. [voice; sound; atmospheres; affect; Islam; Mauritius; South Asia]
\end{abstract}

\title{
NOTES
}

Acknowledgments Fieldwork in Mauritius was made possible by the support of Utrecht University and a generous Vidi grant from the Netherlands Organization for Scientific Research. In Mauritius, I am deeply indebted to Enayet Hossen Edun, Rehana Edun, and their family. Without their support and guidance my research would have been impossible. I also benefited from conversations with Shareef Chady and Fardeen Maraye, who generously shared their knowledge of na't with me. Birgit Abels introduced me to the neo-phenomenological literature on atmospheres, which had already informed her musicological scholarship. Several of the core ideas in this article took shape in long conversations with her, and my intellectual debts to her are obvious. 
1. French has provided most of the vocabulary for Mauritian Creole, but the latter's grammar and morphology are unrelated to French.

2. Merleau-Ponty $(2002,329-30,270)$ drew an explicit link between his use of the concepts of corps vivant and Leib, and made reference to Plessner's 1925 essay.

3. In addition to soundscapes' downplaying of the somatic aspects of listening (see also Daughtry 2015, 122-23), the “-scape” component of soundscapes evokes a stable setting, sidelining the temporality characteristic of sonic events and listening experiences (Ingold 2007; Helmreich 2010).

4. There are resemblances but also significant differences between an analytic of atmospheres and Marcel Jousse's (1990) gestural subject, which Charles Hirschkind (2006, 76-79) has drawn on in his ethnography of cassette-sermon audition in Cairo. Both approaches are concerned with the connections between perception-including sonic perception - and movement. Jousse, however, does not distinguish between felt-body and material body. For him, what matters most are subtle physiological processes in reaction to external stimuli, which result in micromuscular "gestures" that are the base of all expression and memory (Jousse 1990, 23-30). In contrast to the distinction between external phenomena and internal gestures as reactions to stimuli from the outside, the notion of the felt-body central to the analytic of atmospheres stresses the blurring of the boundaries between inside and outside. The felt-body, exceeding the boundaries of the material body, is the ground for mingling with atmospheres as "ecstasies of the thing" (Böhme 1993, 110). Also, feelings are not phenomena that just occur inside the material body; they also take the shape of atmospheres spilling out in nondimensional space: "Feelings are atmospheres poured into [nondimensional] space and powers that seize the felt-body (Leib)" (Schmitz 2014, 30; author's translation). That is, they are entities outside the material body. Their Einleibung, or encorporation in the sense of becoming part of a felt-body, is therefore different from Jousse's (1990, 232-33) "intussusception" of sensory stimuli that trigger gestural reactions (see also Sienaert 1990, 95).

The modification of the felt-body's sense of being in space, as described by Böhme, and Schmitz's suggestions of movement, such as those proper to sonic atmospheres, are therefore different from Jousse's gestures. While the latter's micromuscular dynamics are located in three-dimensional space, atmospheric suggestions of movement unfold in the nondimensional space of the felt-body: "Musical Gestalten are webs of suggestions of movement in the medium of tones, that is, foreshadowings of movement without movement enacted by the music itself (through a shifting of the source of sound)" (Schmitz 2014, 88; author's translation). Thus, Jousse's gestural subject provides a more anthropocentric account of stimulation through sensation indebted to a subject-object divide, while the analytic of atmospheres stresses the intermingling of humans and the world in the felt-body.

5. Sundberg (1974) argued that a marked formant or concentration of acoustic energy in the three- to four-thousand-hertz range enables the voices of European opera singers to be heard over a very loud orchestra.

6. The analyses of the recited excerpts were made using Sonic Visualizer, on the basis of .wav files. Tracking of the fundamental frequency was done with the help of the Vamp plugin Cepstral Pitch Tracker.

7. See Peirce 1932 on the varying degrees of dependence of signification on interpretants. An interpretant, for Peirce, is the condition of being taken as a sign by someone, resulting in the creation of another, related sign in the mind of its interpreter. But this condition is only necessary for a certain class of signs: "An icon is a sign which would possess the character which renders it significant, even though its object had no existence; such as a lead-pencil streak as representing a geometrical line. An index is a sign which would, at once, lose the character which makes it a sign if its object were removed, but would not lose that character if there were no interpretant. Such, for instance, is a piece of mould with a bullet-hole in it as sign of a shot; for without the shot there would have been no hole; but there is a hole there, whether anybody has 
the sense to attribute it to a shot or not. A symbol is a sign which would lose the character which renders it a sign if there were no interpretant. Such is any utterance of speech which signifies what it does only by virtue of its being understood to have that signification" (Peirce 1932, 170). According to Peirce, the iconic and indexical relationships that make up the sonic movements therefore do not depend on mental acts of interpretation. Their significance inheres in their materiality, including contiguities and copresences. Only symbols' signification depends on acts of interpretation.

\section{REFERENCES}

Abels, Birgit

2013 "Hörgemeinschaften: Eine musikwissenschaftliche Annäherung an die Atmosphärenforschung." Musikforschung, no. 3: 220-31.

2017 "Beziehungsweise: Sozial wirksame Präsenzeffekte des Musikalischen." In Stimmungen und Atmosphären: Zur Affektivität des Sozialen, edited by Basil Wiesse and Larissa Pfaller, 217-32. Heidelberg, Germany: Springer.

Agha, Asif

2005 “Voice, Footing, Enregisterment." Journal of Linguistic Anthropology 15, no. 1: 38-59. https://doi.org/10.1525/jlin.2005.15.1.38.

Bakhtin, Mikhail M.

1981 The Dialogic Imagination: Four Essays. Translated by Caryl Emerson and Michael Holquist. Austin: University of Texas Press. Originally published in 1975.

Bakker Kellogg, Sarah

2015 "Ritual Sounds, Political Echoes: Vocal Agency and the Sensory Cultures of Secularism in the Dutch Syriac Diaspora.” American Ethnologist 42, no. 3: 43145. https://doi.org/10.1111/amet.12139.

Barthes, Roland

2012 “The Grain of the Voice." In The Sound Studies Reader, edited by Jonathan Sterne, 504-511. New York: Routledge. Originally published in 1972.

Benade, Arthur H.

1990 Fundamentals of Musical Acoustics. 2nd edition. New York: Dover.

Böhme, Gernot

1993 “Atmosphere as the Fundamental Concept of a New Aesthetics." Thesis Eleven 36, no. 1: 113-26. https://doi.org/10.1177/072551369303600107.

2000 "Acoustic Atmospheres: A Contribution to the Study of Ecological Aesthetics." Soundscape 1, no. 1: 14-18.

2009 "Die Stimme im leiblichen Raum." In Stimm-Welten: Philosophische, medientheoretische und ästhetische Perspektiven, edited by Doris Kolesch, Vito Pinto, Briggs, Charles and Jenny Schrödl, 23-32. Bielefeld, Germany: Transcript.

2014 “Dear Dr. Freud.” Cultural Anthropology 29, no. 2: 312-43. https://doi.org/ 10.14506/ca29.2.08.

Bull, Michael, and Les Back, eds.

2003 The Auditory Culture Reader. New York: Berg.

Cox, Christoph

2011 "Beyond Representation and Signification: Toward a Sonic Materialism." Journal

of Visual Culture 10, no. 2: 145-61. https://doi.org/10.1177/ 1470412911402880 .

Daughtry, J. Martin

2015 Listening to War: Sound, Music, Trauma, and Survival in Wartime Iraq. New York:

Dolar, Mladen Oxford University Press.

2006 A Voice and Nothing More. Cambridge, Mass.: MIT Press.

Downey, Greg

2002 "Listening to Capoeira: Phenomenology, Embodiment, and the Materiality of Music.” Ethnomusicology 46, no. 3: 487-509. https://doi.org/10.2307/852720. 
Erlmann, Veit, ed.

2004 Hearing Cultures: Essays on Sound, Listening, and Modernity. New York: Berg.

Evens, Aden

2002 “Sound Ideas.” In A Shock to Thought: Expression after Deleuze and Guattari, edited by Brian Massumi, 171-87. New York: Routledge.

Faudree, Paja

2012 "Music, Language, and Texts: Sound and Semiotic Ethnography." Annual Review of Anthropology 41: 519-36. https: / / doi.org/10.1146/annurev-anthro-092611145851 .

Feld, Steven

1996 "Waterfalls of Song: An Acoustemology of Place Resounding in Bosavi, Papua New Guinea.” In Senses of Place, edited by Steven Feld and Keith H. Basso, 91135. Santa Fe, N.M.: School of American Research Press.

Feld, Steven, Aaron A. Fox, Thomas Porcello, and David Samuels

2004 "Vocal Anthropology: From the Music of Language to the Language of Song." In A Companion to Linguistic Anthropology, edited by Alessandro Duranti, 321-45. Malden, Mass.: Blackwell.

Gade, Anna M.

2006 "Recitation." In The Blackwell Companion to the Qur'an, edited by Andrew Rippin, 481-93. Malden, Mass.: Blackwell.

Goffman, Erving

1974 Frame Analysis: An Essay in the Organization of Experience. New York: Harper and Row.

Goodman, Steve

2010 Sonic Warfare: Sound, Affect, and the Ecology of Fear. Cambridge, Mass.: MIT Press. Harkness, Nicholas

2011 "Culture and Interdiscursivity in Korean Fricative Voice Gestures." Journal of Linguistic Anthropology 21, no. 1: 99-123. https://doi.org/10.1111/j.15481395.2011.01084.x.

2014 Songs of Seoul: An Ethnography of Voice and Voicing in Christian South Korea. Berkeley: University of California Press.

Helmreich, Stefan

2010 “Listening Against Soundscapes.” Anthropology News 51, no. 9: 10. https:// doi.org/10.1111/j.1556-3502.2010.51910.x.

Henriques, Julian

2003 "Sonic Dominance and the Reggae Sound System Session." In The Auditory Culture Reader, edited by Michael Bull and Les Back, 451-80. New York: Berg.

Hill, Jane H.

1995 "The Voices of Don Gabriel: Responsibility and Self in a Modern Mexicano Narrative." In The Dialogic Emergence of Culture, edited by Dennis Tedlock and Bruce Mannheim, 97-147. Urbana: University of Illinois Press.

Hirschkind, Charles

2006 The Ethical Soundscape: Cassette Sermons and Islamic Counterpublics. New York: Columbia University Press.

Husserl, Edmund

1973 Zur Phänomenologie der Intersubjektivität. The Hague, Netherlands: Martinus Nijhoff. Originally published in 1929-1935.

Ingold, Tim

2007 “Against Soundscape." In Autumn Leaves: Sound and the Environment in Artistic Irvine, Judith T. Practice, edited by Angus Carlyle, 10-13. Paris: Double Entendre.

1996 "Shadow Conversations: The Indeterminacy of Participant Roles." In Natural Histories of Discourse, edited by Michael Silverstein and Greg Urban, 131-59. Chicago: University of Chicago Press. 
Jacobsen-Bia, Kristina

2014 "Radmilla's Voice: Music Genre, Blood Quantum, and Belonging on the Navajo Nation." Cultural Anthropology 29, no. 2: 385-410. https://doi.org/10.14506/ ca29.2.11.

Jouili, Jeanette S., and Annelies Moors

2014 "Introduction: Islamic Sounds and The Politics of Listening." Anthropological Quarterly 87, no. 4: 977-88. https://doi.org/10.1353/anq.2014.0064.

Jousse, Marcel

1990 The Oral Style. Translated by Edgard Sienaert and Richard Whitaker. New York: Garland. Originally published in 1925.

Kane, Brian

2015 "Sound Studies without Auditory Culture: A Critique of the Ontological Turn." Sound Studies 1, no. 1: 2-21. https://doi.org/10.1080/20551940.2015. 1079063.

Kapchan, Deborah

2008 "The Promise of Sonic Translation: Performing the Festive Sacred in Morocco." American Anthropologist 110, no. 4: 467-83. https://doi.org/10.1111/j.15481433.2008.00079.x.

2009 "Learning to Listen: The Sound of Sufism in France." World of Music 51, no. 2: 65-92. http://www.jstor.org/stable/41699883.

Keane, Webb

1999 “Voice." Journal of Linguistic Anthropology 9, nos. 1-2: 271-73. https://doi.org/ 10.1525/jlin.1999.9.1-2.271.

2011 “Indexing Voice: A Morality Tale.” Journal of Linguistic Anthropology 21, no. 2: 166-78. https://doi.org/10.1111/j.1548-1395.2011.01104.x.

Kunreuther, Laura

2006 "Technologies of the Voice: FM Radio, Telephone, and the Nepali Diaspora in Kathmandu." Cultural Anthropology 21, no. 3: 323-53. https://doi.org/ 10.1525/can.2006.21.3.323.

2014 Voicing Subjects: Public Intimacy and Mediation in Kathmandu. Berkeley: University of California Press.

Levinson, Stephen C.

1988 "Putting Linguistics on a Proper Footing: Explorations in Goffman's Concepts of Participation." In Erving Goffman: Exploring the Interaction Order, edited by Paul Drew and Anthony Wootton, 161-227. Cambridge: Polity Press.

Leys, Ruth

2011 “The Turn to Affect: A Critique.” Critical Inquiry 37, no. 3: 434-72. https:// doi.org/10.1086/659353.

Massumi, Brian

2002 Parables for the Virtual: Movement, Affect, Sensation. Durham, N.C.: Duke University Press.

Merleau-Ponty, Maurice

2002 Phenomenology of Perception. Translated by Colin Smith. New York: Routledge.

Nelson, Kristina Originally published in 1945 .

2001 The Art of Reciting the Qur'an. Cairo: American University in Cairo Press.

Parmentier, Richard J.

1994 Signs in Society: Studies in Semiotic Anthropology. Bloomington: Indiana University Press.

Peirce, Charles Sanders

1932 Collected Papers of Charles Sanders Peirce: Volume 2, Elements of Logic. Cambridge, Mass.: Harvard University Press. 
Plessner, Helmuth, with F. J. Buytendijk

1982 "Die Deutung des mimischen Ausdrucks: Ein Beitrag zur Lehre vom Bewusstsein des anderen Ichs." In Gesammelte Schriften, VII: Ausdruck und menschliche Natur, edited by Günter Dux, 67-129. Frankfurt: Suhrkamp. Originally published in 1925.

Sanyal, Usha

1996 Devotional Islam and Politics in British India: Ahmad Riza Khan Barelwi and His Movement, 1870-1920. New York: Oxford University Press.

Schmidt, Leigh Eric

2000 Hearing Things: Religion, Illusion, and the American Enlightenment. Cambridge, Mass.: Harvard University Press.

Schmitz, Hermann

1965 System der Philosophie, Volume 2, 1. Der Leib. Bonn, West Germany: Bouvier.

2005 Situationen und Konstellationen: Wider die Ideologie totaler Vernetzung. Freiburg, Germany: Alber.

2014 Atmosphären. Freiburg, Germany: Alber.

Schmitz, Hermann, Rudolf Owen Müllan, and Jan Slaby

2011 "Emotions Outside the Box: The New Phenomenology of Feeling and Corporeality." Phenomenology and the Cognitive Sciences 10, no. 2: 241-59.

Schrimshaw, Will https://doi.org/10.1007/s11097-011-9195-1.

2013 "Noncochlear Sound: On Affect and Exteriority." In Sound, Music, Affect: Theorizing Sonic Experience, edited by Marie Thompson and Ian Biddle, 27-43. New York: Bloomsbury.

Shouse, Eric

2005 "Feeling, Emotion, Affect." M/C Journal 8, no. 6. http://journal.mediaculture.org.au/0512/03-shouse.php.

Sienaert, Edgard Richard

1990 "Marcel Jousse: The Oral Style and the Anthropology of Gesture." Oral Tradition 5, no. 1: 91-106. http://journal.oraltradition.org/issues/5i/sienaert.

Sterne, Jonathan

2003 The Audible Past: Cultural Origins of Sound Reproduction. Durham, N.C.: Duke University Press.

Sundberg, Johan

1974 “Articulatory Interpretation of the 'Singing Formant'." Journal of the Acoustical Society of America 55, no. 4: 838-44. https://doi.org/10.1121/1.1914609.

Weidman, Amanda

2006 Singing the Classical, Voicing the Modern: The Postcolonial Politics of Music in South India. Durham, N.C.: Duke University Press.

2014 “Anthropology and Voice." Annual Review of Anthropology 43: 37-51. https:// doi.org/10.1146/annurev-anthro-102313-030050.

2015 "Voice." In Keywords in Sound, edited by David Novak and Matt Sakakeeny, 23245. Durham, N.C.: Duke University Press. 